\title{
Gross Motor Development of Malaysian Hearing Impaired Male Pre- and Early School Children
}

\author{
Khairi Zawi ${ }^{1}$, Denise Koh Choon $\operatorname{Lian}^{1}$ \& Rozlina Tan Abdullah ${ }^{1}$ \\ ${ }^{1}$ Faculty of Education, Universiti Kebangsaan Malaysia, Malaysia \\ Correspondence: Khairi Zawi, Faculty of Education, Universiti Kebangsaan Malaysia, 43600 UKM Bangi, \\ Selangor, Malaysia. Tel: 603-8921-6259. E-mail: khairiz@ukm.edu.my
}

Received: July 22, 2014 Accepted: November 5, 2014 Online Published: December 22, 2014

doi:10.5539/ies.v7n13p242 URL: http://dx.doi.org/10.5539/ies.v7n13p242

\begin{abstract}
Acquisition of gross motor skill is a natural developmental process for children. This aspect of human development increases with one's chronological age, irrespective of any developmental conditions. The purpose of this study was to assess the level of gross motor skill development among pre- and early school-aged children with motor disability. A total of 315 hearing-impaired pre- and early school male children in peninsular Malaysia participated in this study. Gross motor development was determined via Ulrich's Test of Gross Motor Development. Overall findings revealed significant differences among pre- and early school gross motor development in terms of locomotors and object manipulation skills. However, significant difference was not observed when both the locomotor and object manipulation skill scores were analyzed based on the Gross Motor Development Quotient (GMDQ) index. Such result indicated that the differences observed for both locomotor and object manipulation skills among pre- and early school-aged children were age-related consequences. However, the absence of significant difference in terms of GMDQ revealed that the differences were not in accordance to improvements that should be observed with increased chronological age.
\end{abstract}

Keywords: gross motor development, hearing disability, locomotor skill, object manipulation

\section{Introduction}

Gross motor skill development among pre- and early school children is a major indicator for their potential to acquire more complex motor skills when they reach physical maturity. This aspect of development is assessed through the performance of selected generic gross motor skills. Gross motor skill refers to the ability to use major muscles groups to perform organized joint movements like walking, running, throwing, jumping, climbing and catching (Williams, 1983). Children ages six to nine years old undergoing normal stages of development would develop reasonable eye-hand and eye-leg coordination to enable them perform fundamental motor actions, such as throwing, catching and hitting with correct coordination, respective of chronological age. These fundamental motor actions represent the foundation to a child's ability to perform more complex motor patterns during the later stages of their motor development (Goodway, Crowe, \& Ward, 2003).

Gross motor development improves as children's age increase. The critical issue is whether improvements observed in gross motor skills are in accordance to the improvements that should be observed during a specific age. Here, the level of general development of gross motor skills during pre- and early school periods may also serve as an indicator to a child's cognitive development (Piek et al., 2008). Children at this stage spend most of their time participating in spatial orientation activities and interacting within the environment through movements like crawling, rolling, walking, and jumping. This stage of development is critical because during this period, the human biological systems are very sensitive to changes. Hence, motor skill development that progresses in tandem with chronological age may provide a reliable predictor of a child's capacity to undergo mainstream education successfully (Roebers et al., 2014).

It is widely acknowledged that progression of motor skill development among motor-disabled children displays significant delays in terms of the biological-chronological age continuum. Children with motor disabilities refer to children who face limitations in mobility to perform their daily living activities. During pre- and early school years, motor-disabled children can be categorized into two groups, which are: (i) children who are at higher risk of failing school, and (ii) children who are disabled based on an act or law in a country (Lerner, Lowerthali, \& Egan, 1998). Here, motor disability terminology may encompass the whole spectrum of disability, from mild 
cases which include; for children with hearing and learning disabilities, to the very serious cases that include Down syndrome and children with cerebral palsy. Delay in gross motor development patterns differ among children with different disabilities. Motor developmental delays inhibit the children's capacity to learn and explore their surrounding environment, thus impeding their cognitive development. This, in turn, reduces the ability of these children to assimilate into mainstream education, which is the ultimate objective of any equal opportunity education program (Sherrill, 2003).

Regardless of the type of disability, gross motor skill is a crucial parameter to monitor the level of development that indicates readiness of children to undergo socialization and public education processes (Gallahue, 1993). As such, the present study intent to assess levels of gross motor development involving Malaysian population is regarded as a necessary preliminary step to trigger more specific research relating to educational interests of the local disabled population.

\section{Premise of Study}

Malaysia aspires to be a developed nation by 2020 . One of the most basic precepts of an advanced nation is the capacity to provide equal education opportunity to all citizens. For physical educators and researchers with profound interest in educational needs of the disabled population, this situation will provide an endearing, yet exciting challenge. Movement is recognized as an indispensable part of learning. Many educators and researchers agree that the brain is activated during physical activity, and that movement is essential to learning (e.g., Hannaford, 1995; Summerford, 2000). For children with any forms of disability, movement is central to allow learning to take place. Ability to move permits the social process among peers, and it is through this socialization that children with disability will eventually experience the fundamental process of formal education (Sherrill, 2003). Figure 1 illustrates the basis of our research premise. The present report represented a preliminary aspect of the overall research framework.

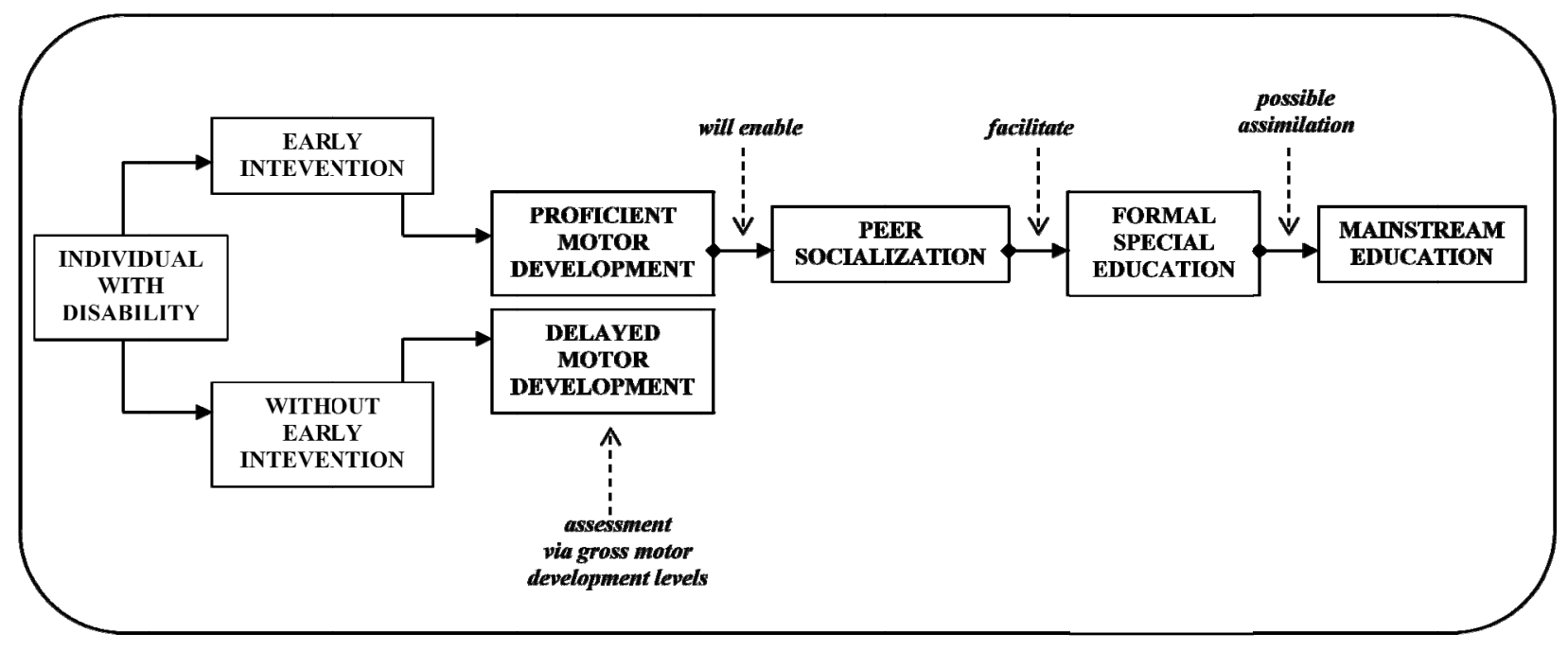

Figure 1. Premise of research to illustrate potential pathway for an individual with disability to experience possible assimilation into mainstream education

This research is focused on children with hearing impairment. Hearing impaired condition in humans may be congenital or acquired. Individuals who are born with hearing impairment will usually be mute due to deprivation of audio stimulation that disables the development of oral communication skills. Thus, childhood hearing impairment is a chronic condition that may have a profound impact on their social and physical development. Damage to the auditory system affects the vestibular functions, which may result in accompanying balance and motor disorders (Rajendran \& Roy, 2011). Poor balance control, in turn, affects gross motor development. Failure to effectively control balance during movement is one of the main factors hampering motor development among children. Therefore, children with hearing disability need basic motor control and balance to enable them to achieve a level of motor development in line with their chronological age.

The major purpose of this study is to determine locomotors and object manipulation skills development among 
children with hearing disability in pre-schools and early schools in Malaysia. We hypothesized that normal patterns for skill development of locomotors and object manipulation will be observed across all age groups in this study, with expected proficiency displayed among the older age groups.

\section{Methodology}

This study employed an ex post facto design. Levels of gross motor development were compared on the basis of chronological age, and their schooling year. Ulrich's Test of Gross Motor Development (Ulrich, 1985) was used to assess gross motor development. The reliability of Ulrich Test of Gross Motor Development is $r=0.96-0.97$. The Ulrich Test of Gross Motor Development used in this study is based on the first version, which includes two aspects of gross motor skills, as follows: seven items of locomotors skills, and five items of object manipulation skills (Ulrich, 1985). This test is sensitive towards gross motor performance among children aged between three to ten years old. The 1985 version of this instrument was chosen over the 2001 version (Ulrich, 2001) because of the inclusion of skipping component, whereas the later version replaced the skipping component with underhand roll. Assessment of skipping skill is crucial among children with impaired hearing. Skipping emphasizes balance and general dynamic coordination, and hearing-impaired children reported deficits in these motor aspects are well-documented (e.g., Butterfield, 1986; Savelsbergh et al., 1991; Siegel, Marchetti \& Tecklin, 1991; Gheysen, Loots, \& Waelvelde, 2007). These aspects necessitated the utilization of the earlier version of the instrument.

\subsection{Sample and Implementation}

A total of 315 hearing-impaired male children, aged between six to 10 years old from various ethnic groups and from different states in Peninsular Malaysia were recruited for this study. Here, the general categorization of hearing impairment was on the basis of the children's enrolment in national institutions for individual with hearing disability. Ulrich's Test of Gross Motor Development distinguishes the standard scores conversion from the raw scores among males and females for object manipulation skills. Determination of GMDQ scores dependent upon these standard scores. Therefore, separate analyses for male and female gross motor performances will be required. It is the specific intent of this report to evaluate gross motor performance of male children only.

Data collection was assigned according to zones, as indicated in Table 1. All preschool participants in this study were enrolled in private schools for special children, whereas the early school participants were enrolled in public special schools for children with hearing disability. School and parental consent was obtained from all participants. Participation in this study was on voluntary basis.

Table 1. Data collection zones and comprising states

\begin{tabular}{lll}
\hline Data collection zones & Peninsular states & Number of participants \\
\hline North & Perlis, Kedah, Penang & 70 \\
East Coast & Kelantan, Terengganu, Pahang & 67 \\
Central & Perak, Selangor, Federal Territory & 103 \\
South & Negeri Sembilan, Melaka, Johor & 75 \\
\hline
\end{tabular}

Participants were required to complete the locomotors skills protocol before proceeding to the object manipulation skills. For each test item, participants' motor performance were assessed according to specific criteria associated to the particular gross motor skill (refer to Ulrich [1985] for more detailed information regarding assessment criteria). The skills tested in each item will be demonstrated to the participants before allowing them to undergo the test. Participants were accorded two trials to complete each skill before their performance is assessed and recorded. Performance scores were based on the better trial of the two. Apart from motor performance, demographic data such as type of intervention that each child is undergoing for their hearing disability, and type of schooling, were also collected from all participants in the study. Such demographic data may provide certain insights with regards to the participants' social aspects, but is not deliberated in this report.

\subsection{Data Collection Procedure}

Performance scores were assessed based on the stated criteria for each test item. A score of 1 will be given for each criterion where the movement of the child meets the stated criteria. Sets of criteria vary according to test items. Raw scores were also subjected to standard scores transformation for the purpose of obtaining GMDQ. Tables 2-5 indicated the transformation of raw scores to standard scores, and from the standard scores to 
GMDQ.

Table 2. Example of obtaining raw score for a locomotor subtest

\begin{tabular}{llll}
\hline Item & Criteria & Trial 1 & Trial 2 \\
\hline RUN & (a) Arms move in opposition to legs, elbows flexed & 1 \\
& (b) Brief period where both feet are off the ground & 0 \\
(c) Narrow foot placement landing on heel or toe (i.e., not flat footed) & 1 \\
(d) Non-support leg bent approximately 90 degrees & 0 \\
\hline TOTAL RAW SCORE & 2 \\
\hline
\end{tabular}

Raw scores were transformed into standard scores based on participants' age (see Tables 3 and 4). For example, if an eight-year-old participant scored 18 points on locomotors skills test, then his standard score would be five. Similarly, if he scored 12 points on object manipulation skills test, the corresponding standardised score will be six. From these examples, the total standardized score for this participant would be 11. Finally, based on Table 5, the corresponding GMDQ score for this participant is 73.

Table 3. Standard scores for locomotor

\begin{tabular}{|c|c|c|c|c|c|c|c|c|c|}
\hline \multirow{2}{*}{$\begin{array}{l}\text { Standard } \\
\text { Score }\end{array}$} & \multicolumn{8}{|c|}{ Age } & \multirow{2}{*}{$\begin{array}{l}\text { Percentile } \\
\text { Rank }\end{array}$} \\
\hline & 3 & 4 & 5 & 6 & 7 & 8 & 9 & 10 & \\
\hline 1 & 0 & $0-3$ & $0-3$ & $0-4$ & $0-5$ & $0-8$ & $0-9$ & $0-13$ & \\
\hline 2 & 1 & 4 & $4-6$ & $5-6$ & $6-7$ & $9-12$ & $10-12$ & $14-16$ & $<1$ \\
\hline 3 & 2 & 5 & 7 & 7 & $8-10$ & $13-15$ & $13-16$ & 17 & 1 \\
\hline 4 & 3 & - & $8-9$ & $8-10$ & 11 & $16-17$ & $17-18$ & 18 & 2 \\
\hline 5 & - & 6 & 10 & $11-12$ & $12-15$ & 18 & 19 & 19 & 15 \\
\hline 6 & 4 & 7 & $11-12$ & 13 & 16 & $19-20$ & 20 & $20-21$ & 9 \\
\hline 7 & 5 & 8 & 13 & $14-15$ & 17 & 21 & 21 & 22 & 16 \\
\hline 8 & 6 & 9 & 14 & 16 & $18-19$ & 22 & 22 & 23 & 25 \\
\hline 9 & 7 & $10-11$ & 15 & 17 & 20 & 23 & 23 & 24 & 37 \\
\hline 10 & $6-9$ & 12 & 16 & $18-19$ & 21 & 24 & 24 & 25 & 50 \\
\hline 11 & - & 13 & 17 & 20 & 22 & - & - & - & 63 \\
\hline 12 & 10 & $14-15$ & $18-19$ & 21 & 23 & 25 & 25 & 26 & 75 \\
\hline 13 & 11 & 16 & $20-21$ & $22-23$ & 24 & - & - & & 84 \\
\hline 14 & 12 & 17 & $22-23$ & - & 25 & 26 & 26 & & 91 \\
\hline 15 & 13 & 18 & 24 & 24 & 26 & & & & 95 \\
\hline 16 & 14 & 19 & $25-26$ & $25-26$ & & & & & 98 \\
\hline 17 & - & $20-46$ & & & & & & & 99 \\
\hline 18 & 15 & & & & & & & & 99 \\
\hline 19 & $16-26$ & & & & & & & & \\
\hline 20 & & & & & & & & & \\
\hline
\end{tabular}

Note. Source: Ulrich, D.A. (1985) Test of gross motor development. 
Table 4. Standard scores for object manipulation

\begin{tabular}{|c|c|c|c|c|c|c|c|c|c|}
\hline \multirow{2}{*}{$\begin{array}{l}\text { Standard } \\
\text { Score }\end{array}$} & \multicolumn{8}{|c|}{ Age } & \multirow{2}{*}{$\begin{array}{l}\text { Percentile } \\
\text { Rank }\end{array}$} \\
\hline & 3 & 4 & 5 & 6 & 7 & 8 & 9 & 10 & \\
\hline 1 & & & & $0-1$ & $0-3$ & $0-4$ & $0-5$ & $0-6$ & \\
\hline 2 & & & 0 & 2 & 4 & 5 & $6-7$ & 7 & $<1$ \\
\hline 3 & & 0 & 1 & 3 & 5 & $6-9$ & $8-9$ & $8-12$ & 1 \\
\hline 4 & & 1 & - & - & - & 10 & $10-11$ & $13-14$ & 2 \\
\hline 5 & 0 & 2 & 2 & 4 & 6 & 11 & - & 15 & 15 \\
\hline 6 & - & - & 3 & 5 & $7-8$ & 12 & 12 & 16 & 9 \\
\hline 7 & 1 & 3 & 4 & 6 & $9-10$ & 13 & 13 & - & 16 \\
\hline 8 & - & - & 5 & $7-8$ & 11 & 14 & $14-15$ & 17 & 25 \\
\hline 9 & 2 & 4 & 6 & 9 & $12-13$ & 15 & 16 & - & 37 \\
\hline 10 & - & - & 7 & 10 & 14 & 16 & 17 & 18 & 50 \\
\hline 11 & 3 & 5 & 8 & 11 & 15 & 17 & - & - & 63 \\
\hline 12 & - & 6 & $9-11$ & $12-13$ & 16 & - & 18 & - & 75 \\
\hline 13 & 4 & 7 & $12-13$ & 14 & 17 & 18 & - & 19 & 84 \\
\hline 14 & 5 & - & $14-15$ & 15 & 18 & - & 19 & & 91 \\
\hline 15 & $6-8$ & 8 & $16-17$ & $16-17$ & - & 19 & & & 95 \\
\hline 16 & $9-10$ & 9 & 18 & $18-19$ & 19 & & & & 98 \\
\hline 17 & $11-12$ & $10-12$ & 19 & & & & & & 99 \\
\hline 18 & 13 & $13-15$ & & & & & & & $>99$ \\
\hline 19 & 14-19 & 16-19 & & & & & & & \\
\hline 20 & & & & & & & & & \\
\hline
\end{tabular}

Note. Source: Ulrich, D.A. (1985) Test of gross motor development.

Table 5. GMDQ conversion from standard scores

\begin{tabular}{llll}
\hline Total of standard scores & Quotient & Total of standard scores & Quotient \\
\hline 38 & 154 & 20 & 100 \\
37 & 151 & 19 & 97 \\
36 & 148 & 18 & 94 \\
35 & 145 & 17 & 91 \\
34 & 142 & 16 & 88 \\
33 & 139 & 15 & 85 \\
32 & 136 & 14 & 82 \\
31 & 133 & 13 & 79 \\
30 & 130 & 12 & 76 \\
29 & 127 & 11 & 73 \\
28 & 124 & 10 & 70 \\
27 & 121 & 9 & 67 \\
26 & 118 & 8 & 64 \\
25 & 115 & 7 & 61 \\
24 & 112 & 6 & 58 \\
\hline
\end{tabular}




\begin{tabular}{llll}
\hline 23 & 109 & 5 & 55 \\
22 & 106 & 4 & 52 \\
21 & 103 & 3 & 49 \\
& & 2 & 46 \\
\hline
\end{tabular}

Note. Source: Ulrich, D.A. (1985) Test of gross motor development.

\subsection{Data Analysis}

Standardized locomotors skills, object manipulation and GMDQ scores were described using mean and standard deviation. Data were subjected to Kalmogorov-Smirnov and Hartley $F_{\max }$ tests to ensure assumptions of normality and homogeneity of variance were not violated. One-way ANOVA and Fisher's LSD post hoc were conducted to explore differences that might exist between the age groups in terms of the three mentioned parameters. For all comparisons, significance level was predetermined at $95 \%$ level. Effect sizes were determined via omega squared $\left(\omega^{2}\right)$ calculation.

\section{Results}

\subsection{Locomotor Tests Results}

Table 6 summarizes the mean and standard deviation for locomotor skills scores.

Table 6. Mean and standard deviation for locomotor scores based on age groups

\begin{tabular}{llll}
\hline Age & N & Mean & Standard deviation \\
\hline 6 & 45 & 13.733 & 6.713 \\
7 & 41 & 16.000 & 6.899 \\
8 & 75 & 19.320 & 4.899 \\
9 & 75 & 20.828 & 4.654 \\
10 & 79 & 21.000 & 5.066 \\
\hline & 315 & 19.863 & 5.428 \\
\hline
\end{tabular}

Mean scores for locomotors skills increased with age, and one way ANOVA test indicated that these score increments across age groups were significant $[\mathrm{F}(4,310)=10.726, \mathrm{p}<.05]$. Post hoc analysis revealed that locomotors skills scores for six and seven year old children were not significantly different, but the locomotors skill scores for children aged eight, nine and ten were significantly higher compared to the six year olds $(\mathrm{p}<.05)$. Owing to the large effect size, we safely concluded that notable locomotors skills improvement for male Malaysian hearing-impaired children only occur during the later stage of their early school years.

Table 7. One way ANOVA for locomotor skills

\begin{tabular}{lllllll}
\hline & Source & SS & df & MS & F ratio & $\mathrm{p}$ \\
\hline Locomotor & Between & 1124.96 & 4 & 281.241 & 10.726 & $.001^{*}$ \\
& Within & 8128.16 & 310 & 26.220 & & \\
& Total & 9253.13 & 314 & & & \\
\hline
\end{tabular}

Note. $\omega^{2}=0.11$, *Significant at $\alpha=.05$. 
Table 8. Summary for Fisher LSD Post Hoc Analysis for Locomotor Skills

\begin{tabular}{llll}
\hline Preschool & Early school & Mean differences & $\mathrm{p}$ \\
\hline 6 & 7 & -2.266 & .686 \\
& 8 & -5.586 & $.001 *$ \\
& 9 & -7.095 & $.000^{*}$ \\
& 10 & -7.266 & $.000 *$ \\
\hline
\end{tabular}

\subsection{Object Manipulation Test Results}

Table 9 summarizes the mean and standard deviation for object manipulation skills scores.

Table 9. Mean and standard deviation for object manipulation scores based on age groups

\begin{tabular}{llll}
\hline Age & $\mathbf{N}$ & Mean & Standard deviation \\
\hline 6 & 45 & 10.866 & 4.688 \\
7 & 41 & 11.190 & 4.621 \\
8 & 75 & 13.426 & 3.859 \\
9 & 75 & 14.790 & 3.882 \\
10 & 79 & 15.818 & 3.417 \\
\hline & $\mathbf{3 1 5}$ & $\mathbf{1 4 . 3 6 1}$ & $\mathbf{4 . 0 8 4}$ \\
\hline
\end{tabular}

The same pattern of results was observed for object manipulation skills test scores. As per locomotors scores, mean scores for the object manipulation skills increased with age. One-way ANOVA yielded significant difference for the performance increase across age groups $[\mathrm{F}(4,310)=11.742, \mathrm{p}<.05]$. However, post hoc analysis revealed only the standardized mean scores of nine and ten year old children were significantly different from the six year old group $(p<.05)$. This finding did not replicate the development trend observed in locomotors skills. Here, significant object manipulation skills improvement for Malaysian hearing-impaired male children occur at a much later stage of the early school period, as compared to age-based improvements evidenced in locomotors skills.

Table 10. One way ANOVA for object manipulation skills

\begin{tabular}{lllllll}
\hline & Source & SS & df & MS & F ratio & p \\
\hline Object & Between & 689.307 & 4 & 172.327 & 11.742 & $.000 *$ \\
manipulation & Within & 4549.436 & 310 & 14.676 & & \\
& Total & 5238.743 & 314 & & & \\
\hline
\end{tabular}

Note. $\omega^{2}=0.12, *$ Significant at $\alpha=.05$.

Table 11. Summary for Fisher LSD post hoc analysis for object manipulation skills

\begin{tabular}{llll}
\hline Preschool & Early school & Mean differences & $\mathrm{p}$ \\
\hline 6 & 7 & -0.323 & .299 \\
& 8 & -2.560 & .128 \\
& 9 & -3.923 & $.002^{*}$ \\
& 10 & -4.951 & $.001^{*}$ \\
\hline
\end{tabular}




\subsection{GDMQ Results}

Table 12 summarizes the mean and standard deviation for GMDQ scores.

Table 12. Mean and Standard Deviation for GMDQ Based On Age Groups

\begin{tabular}{llll}
\hline Age & N & Mean & Standard deviation \\
\hline 6 & 45 & 92.400 & 23.012 \\
7 & 41 & 84.904 & 22.043 \\
8 & 75 & 84.080 & 19.752 \\
9 & 75 & 89.514 & 21.230 \\
10 & 79 & 85.252 & 20.844 \\
\hline & $\mathbf{3 1 5}$ & $\mathbf{8 6 . 7 1 1}$ & $\mathbf{2 0 . 9 3 2}$ \\
\hline
\end{tabular}

Analysis of the GDMQ revealed that the mean scores were not significantly different between children ages six till ten $[F(4,310)=1.206, p>0.05]$. This finding is most critical as it indicated that differences found in the locomotors and object manipulation skills scores earlier were due to physical growth that normally accompanies age-related developmental changes. GMDQ index represents the expected level of gross motor skill that corresponds to increase in chronological age. Hence, the non-significant finding here further suggests that normal level of gross motor development pattern was not observed among pre- and early school Malaysian hearing-impaired male children.

\section{Discussion and Conclusion}

Overall, this study aimed to determine the gross motor developmental levels of Malaysian male children with hearing impairment during their preliminary schooling period. GDMQ, which represents a composite index for fundamental locomotors and object manipulation skills, was used to assess and compare gross motor development levels between pre-school children and early primary school children. The intention for such assessment and comparison is to gather certain insights with regards to the role of preschool and early school institutions in facilitating gross motor development of the said population. Here, the findings should provide specific direction with regards to the manner we should proceed to further the research pertaining equal opportunity education for the disabled population. Potential benefit of this study is three-fold. Firstly, the focus of evaluation for these children is primarily on language development. Thus, to minimize the adverse effects on normal development of hearing disorders, it is crucial to carry out screening procedures assessing balance and motor deficits which enable early detection of these dysfunctions. Secondly, it is pertinent to re-evaluate gross motor functions of hearing-impaired children during the course of their pre- and early school years in order to assure proper early intervention. Finally, the need to determine gross motor development levels in these children is important as a reference point for future studies that attempt to evaluate the effectiveness of the Special Education in the National School system, specifically the Physical Education curriculum.

On the gross motor development aspect, this study found that mean GDMQ scores of Malaysian hearing impaired male children aged six years old recorded higher values compared to children ages seven to 10 . Though statistically not significant, the lack of increment of GDMQ scores from children ages six to 10 allowed the following conclusion: (i) physical growth, that come with structural changes, does influence locomotors and manipulative skills among children with hearing impairment; (ii) the lack of significant difference on GDMQ scores between children aged six to 10 , but the significant increases in the locomotors and object manipulation skills scores observed in this study implies that the developmental milestone in this population was purely a consequence of physical changes that accompany the increase in chronological age; (iii) gross motor developmental milestone observed among children with hearing impairment in this study hinted that these children did not develop according to their chronological age, and (iv) findings from this study indicated that to a certain extent, the Special Education physical education curriculum practiced in Malaysian public schools does not facilitate gross motor development in accordance to changes in chronological age among children with hearing impairment. Main finding from this study revealed that normal patterns of gross motor development was not evident among pre-school and early primary school hearing impaired male children in public schools. This finding is consistent with a previous study that found children with special needs deprived of necessary 
interventions, did not experience gross motor development in line with their chronological age (Rine et al., 2004).

The main finding of this study supported the perceived lack of emphasis on gross motor development among early primary school children with hearing impairment in the Malaysian public school system. A further study is warranted to determine whether such lack of emphasis may be due to: (i) the non-existence of a systematic and uniformed physical intervention programmes in the national public schools for children with hearing impairments, (ii) lack of effective intervention programmes for children with special hearing needs in the national public school for special education, or (iii) whether the lack of intervention programmes, or the lack of proper implementation of planned intervention programmes at public schools, may be due to the teachers' lack of training to offer necessary intervention that assures hearing-impaired children's' gross motor skills develop in accordance to their chronological age (e.g., Goodway \& Branta, 2003). Further, the focus for children with hearing impairments traditionally focuses on language acquisition. Therefore, opportunities are rather scarce for hearing impaired children to participate in systematic physical education activities (e.g., Gheysen et al., 2007; Rajendran \& Roy, 2011). Regular well-planned physical activity participation to advocate active lifestyles is critical to ensure children with hearing impairment will experience normal patterns of gross motor development (e.g., Barnett, van Beurden, \& Morgan, 2009).

In summary, among the main objectives of Malaysian National Education Policy is to nurture holistic individual, with parallel importance on development of the cognitive, psychomotor, and affective domains. The main finding of this study shows that the psychomotor objective is not met among early school male children with hearing impairment. Hence, we presumed that an evaluation of the special physical education curriculum in public national schools is overdue. We further recommend that the evaluation be qualitative in nature, in order to identify specific aspects in the teaching and learning process in special physical education that potentially hinders normal patterns of gross motor development among early school children with hearing impairment. Based on findings from this study, evaluation of gross motor development among other children under the special education curriculum in public schools (i.e., children with autism, intellectual disability, and specific learning disorders) may be warranted. This evaluation might provide sufficient grounds for policy changes and revamp of the national special education curriculum should poor levels of gross motor development are also prevalent among children with other forms of disability. If similar results are not replicated in other special needs population, a more specific study among children with hearing impairment, with inclusion of crucial demographic parameters such as ethnicity and socioeconomic background, ought to be carried out. These studies are imperative in ensuring that special needs children in public national schools are also provided the opportunity to develop as holistically as children undergoing the mainstream education.

\section{References}

Anderson, K. L., \& Matkin, N. D. (1991). Hearing conversation in the public schools revisited. Seminars in Hearing, 12, 340-364.

Annie, G. S., \& Carol, A. K. (1999). Hearing: Sounds and silences. In M. L. Batshaw (Ed.), Children with disabilities (pp. 241-274). Baltimore, MD: Paul. H. Brookes.

Barnett, L. M., van Beurden, E. \& Morgan, P. J. (2009). Childhood motor skill proficiency as a predictor of adolescent physical activity. Journal of Adolescent Health, 44, 252-259.

Burton, A. W. (1998). Movement skill assessment. Champaign, IL: Human Kinetics.

Butterfield, S. A. (1986). Gross motor profiles of deaf children. Perceptual and Motor Skills, 62, 68-70. http://dx.doi.org/10.2466/pms.1986.62.1.68

Clark, J. E. (1994). Motor Development. In V. S. Ramachandran (Ed.), Encyclopedia of human behavior, 3, 245-255.

Fischer, K. W., \& Farrar, M. J. (1988). Generalization about generalization: how a theory of skill development explains both generality and specificity. The Neo-Piagetian Theories of Cognitive Development: Toward an Integration. North Holland: Elsevier.

Gallahue, D. L. (1993). Developmental physical education for today's children (2nd ed.). Dubuque, IA: Wm C. Brown.

Gheysen, F., Loots, G., \& Waelvelde, H. V. (2007). Motor development of deaf children with and without cochlear implants. Journal of Deaf Studies and Deaf Education, 13, 215-224. http://dx.doi.org/10.1093/deafed/enm053 
Goodway, J. D., \& Branta, C. F. (2003). Influence of motor skill intervention on fundamental motor skill development of disadvantaged preschool children. Research Quarterly for Exercise and Sport, 74, 36-38. http://dx.doi.org/10.1080/02701367.2003.10609062

Goodway, J. D., Crowe, H., \& Ward, P. (2003). Effects of motor skill instruction on fundamental motor skill development. Adapted Physical Activity Quarterly, 20, 298.

Handen, B. L., Jonosky, J., \& McAuliffe, S. (1994). Classroom behavior: Comparison of children with and without ADHD. Journal of Abnormal Child Psychology, 22, 267-280.

Hannaford, C. (1995). Smart moves: Why learning is not all in your head. Salt Lake City, UT: Great River Books.

Hayes, E. (1988). A Commitment to quality daily physical education: A case study in Chillwack. B.C. CAHPER Journal, 54, 12-16.

Hestenes, L. L., Carpenter, E. S., \& Innes, F. K. (1997). Relationships between enrollment in an inclusive class and preschool children's ideas about people with disabilities. Topics in Early Childhood Special Education, 174, 520-536. http://dx.doi.org/10.1177/027112149701700409

Kittrell, A. E., Giarardi, M., Konrad, H. R., Huges, L. F., \& Neill, M. (1998). Rehabilitation for hearing impaired children should include treatment for ear-related balance problems. American Academy of Otolaryngology-Head and Neck Surgery Foundation, 13-16.

Lerner, J. W., Lowerthali, B., \& Egan, R. (1998). Preschool children with special needs: Children at-risk. Children with Disabilities. Boston, MA: Allyn \& Bacon.

Odom, S. L., \& McEvoy, M. A. (1988). Integration of young children with handicaps and normal developing children. Infants and Children with handicaps: An empirical base. Baltmore, MD: Paul. H. Brookes.

Piek, J. P., Dawson, L., Smith, L. M., \& Gasson, N. (2008). The role of early fine and gross motor development on later motor and cognitive ability. Human Movement Science, 27(5), 668-681. http://dx.doi.org/10.1016/j.humov.2007.11.002

Rajendran, V., \& Roy, F. G. (2011). An overview of motor skill performance and balance in hearing impaired children. Italian Journal of Pediatrics, 37, 33. http://dx.doi.org/10.1186/1824-7288-37-33

Rine, R. M., Braswell, J., Fisher, D., Jotce, K., Kalar, K., \& Shaffer, M. (2004). Improvement of motor development and postural control following intervention in children with sensorineural hearing loss and vestibular impairment. International Journal of Pediatric Otorhinolaryngology, 1-7.

Roebers, C. M., Rothlisberger, M., Neuenschwander, Cimeli, P., Michel, E., \& Jager, K. (2014). The relation between cognitive and motor performance and their relevance for children's transition to school: A latent variable approach. Human Movement Science, 33, 284-297.

Santrock, J. W. (2001). Child development. New York: McGraw Hill.

Savelsbergh, G. J. P., Netelenbos, J. B., \& Whiting, H. T. A. (1991). Auditory perception and the control of spatially coordinated action of deaf and hearing impaired children. Journal of Child Psychology and Psychiatry, 32, 489-500. http://dx.doi.org/10.1111/j.1469-7610.1991.tb00326.x

Sherrill, C. (2003). Adapted physical activity, recreation and sport: Crossdisciplinary and lifespan (5th ed.). Boston, MA: McGraw-Hill.

Siegel, J. C., Marchetti, M., \& Tecklin, J. S. (1991). Age-related balance changes in hearing-impaired children. Physical Therapy, 71, 183-189.

Summerford, C. (2000). Teaching lifelong health and fitness: A brain-compatible thematic approach. Champaign, IL: Human Kinetics.

Thomas, G., \& Feiler, A. (1988). Planning for special needs. A whole school approach. London: Jessica Kingsley.

Ulrich, D. A. (1985). Test of gross motor development. Austin, TX: PRO-ED.

Ulrich, D. A. (2001). Test of gross motor development (2nd ed.). Austin, TX: PRO-ED.

Vlachou, M., \& Farrell, P. (2000). Object mastery motivation in pre-school children with and without disabilities. Educational Psychology, 20, 167-177. http://dx.doi.org/10.1080/713663715

Wiegersma, P. H., \& Van der Velde, A. (1983). Motor development of deaf children. Journal of Child Psychology and Psychiatry, 24, 103-111. 
William, H. G. (1983). Perceptual and motor development. Englewood Cliffs, NJ: Prentice-Hall.

Wong, T. P. S., Leung, E. Y. W., Poon, C. Y. C., Leung, C. Y. F., \& Lau, B. P. H. (2103). Balance performance in children with unilateral and bilateral severe-to-profound-grade hearing impairment. Hong Kong Physiotherapy Journal, 31, 81-87. http://dx.doi.org/10.1016/j.hkpj.2013.07.001

\section{Copyrights}

Copyright for this article is retained by the author(s), with first publication rights granted to the journal.

This is an open-access article distributed under the terms and conditions of the Creative Commons Attribution license (http://creativecommons.org/licenses/by/3.0/). 